\title{
Bilateral branch retinal artery occlusion in a child with nephrotic syndrome
}

\author{
Srikanta Kumar Padhy, Tapas Ranjan Padhi, Utpal Bhusal, Krushna Gopal Panda
}

Vitreoretinal services, Mithu Tulsi Chanrai Campus, LV Prasad Eye Institute, Bhubaneswar Campus, Bhubaneswar, Odisha, India

\section{Correspondence to} Dr Tapas Ranjan Padhi; tapaspadhi254@gmail.com

Accepted 17 April 2020
Check for updates

(C) BMJ Publishing Group Limited 2020. No commercial re-use. See rights and permissions. Published by BMJ.

To cite: Padhy SK, Padhi TR, Bhusal U, et al. BMJ Case Rep 2020;13:e235689. doi:10.1136/bcr-2020235689

\section{DESCRIPTION}

A 5 -year-old girl was referred to our retina clinic with the chief problem of painless diminution of vision in both eyes for 1.5 years, more so in the last 1 month. Medical records showed that she had been on oral steroid and immunomodulator (cyclosporine) for nephrotic syndrome (NS) (biopsy proven minimal change disease) for last 6 months. She was also under treatment for dyslipidaemia. At presentation, her best corrected visual acuity was 20/400 in the right eye and 20/40 in the left eye. The pupils were round, regular and reacting to light in both the eyes without any afferent pupillary defect. Slit lamp examination showed an unremarkable anterior segment with an intraocular pressure of 17 and $14 \mathrm{~mm} \mathrm{Hg}$ in the right and left eyes, respectively. Colour vision with Ishihara pseudoisochromatic chart was unremarkable in the left eye, while she could not even read the demo plate in the right eye. Fundus examination of both the eyes showed temporal disc pallor, bright internal limiting membrane reflex over posterior pole except nasally over the areas of retinal thinning and retinal pigment epithelial (RPE) alteration between the disc and fovea (figure 1A,B). There were sclerosed arterioles just inferotemporal to optic disc in both eyes better appreciated in autofluorescence imaging (figure 1C,D). Horizontal trans foveal line scan revealed inner retinal thinning with preservation of outer retinal layers and thickened choroid in both the eyes (figure 2A,B). The entire nasal half of the macula was found to be thinned in the macular thickness map in both the eyes(figure 2C-F). Fundus fluorescein angiography could not be done because of preexisting renal pathology. Based on the above, she was diagnosed to be a case of resolved branch retinal artery occlusion in both the eyes. The girl was referred to the treating physician who advised subcutaneous low molecular weight heparin based on systemic coagulation profile.

NS, a common renal disorder in childhood, with a worldwide incidence between 1.52 and $16.9 / 100000 /$ year, is characterised by a deranged renal filtering system. ${ }^{1}$ The clinical and biochemical features are attributed to the heavy proteinuria $>40 \mathrm{mg} / \mathrm{m}^{2} /$ hour, resulting in hypoalbuminemia $(<2.5 \mathrm{~g} / \mathrm{dL})$, hypercholesterolemia and anasarca. Minimal change disease is the most common cause of NS in paediatric population. Though the exact pathogenesis remains unknown, autoimmunity plays an important role in altering the integrity of the glomerular basement membrane leading to intense proteinuria and intravascular protein depletion. ${ }^{2}$ Next to infection, thromboembolism is often

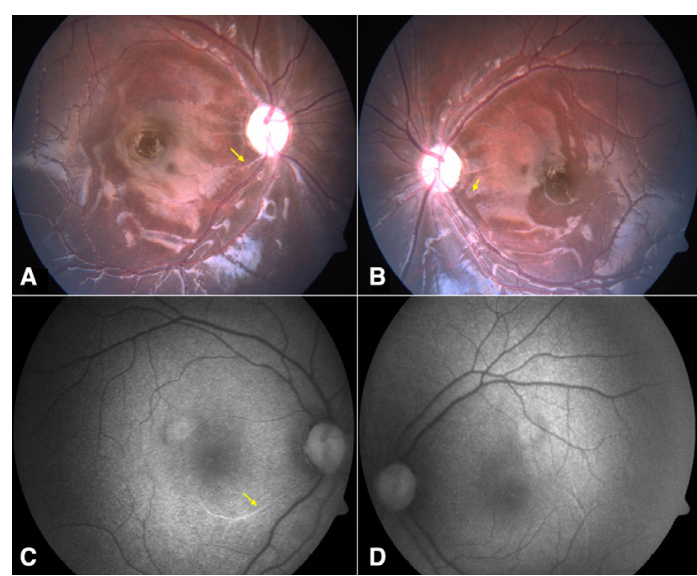

Figure 1 Colour fundus photographs of bilateral eyes show temporal optic disc pallor, areas of retinal thinning with bright internal limiting membrane reflex nasal to fovea, sclerosed arteries temporal to disc with localised thinning and retinal pigment epithelial (RPE) alteration in the area between the disc and fovea at the posterior pole ( $A$ and $B$ ) and sclerosed arteries could be better appreciated in autofluorescence image (C and D).

considered as the most significant life-threatening complication of NS. ${ }^{3}$ Hypovolemia, haemoconcentration, dyslipidaemia, urinary loss of anticoagulants like antithrombin III, proteins $\mathrm{C}$ and S, increase in circulating fibrinogen, factors $\mathrm{V}$ and VIII, and diminished fibrinolytic activity leads to a hypercoagulable stage in $97 \%$ of these patients. Though most of the thromboembolic events occur
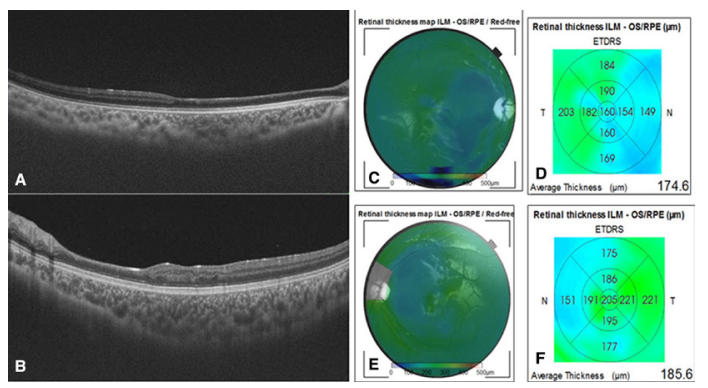

Figure 2 Swept source optical coherence tomography of bilateral eyes shows the presence of symmetrical bilateral thinning of inner retinal layers nasal to fovea along the papillomacular bundle with preservation of outer retinal layers ( $A$ and $B$ ) with features being better appreciated in retinal thickness map (C-F). ETDRS, Early Treatment Diabetic Retinopathy Study; ILM, Internal Limiting Membrane; OS, left eye; RPE, retinal pigment epithelium. 
within the first 6 months of the disease, it can occur at any time during the disease course. ${ }^{4}$

Ocular manifestations of NS, including posterior subcapsular cataract, increased intraocular pressure, ptosis and keratitis, are mostly related to prolonged corticosteroid usage. ${ }^{5}$ Retinal vascular involvement has rarely been reported and could be secondary to hypertension or arterial or venous thromboembolism. Sinha et al has reported a case of bilateral combined central retinal artery and vein occlusion in a 3-year-old child with NS with good visual recovery after systemic treatment. ${ }^{6}$ However, a possible diagnosis of Purtscher-like retinopathy was suspected by Dwivedi et al for the above reported case in their letter to editor. ${ }^{7}$ Dwivedi et al have reported a case of Purtscher-like retinopathy in a 12-year-old male child with steroid-dependent NS with multiple episodes of relapse. ${ }^{8}$

The visual outcome depends on the type and extent of retinal vasculature involved, timing of presentation and prompt intervention, if any. While a large embolus can block central retinal artery, the smaller ones can block a branch retinal artery, precapillary arteriole or distal capillaries leading to branch retinal artery occlusion, Purtscher flecken or cotton wool spot,

\section{Patient's perspective}

We are happy that our daughter's disease could be diagnosed at an early stage so as to avail of immediate further consult and treatment. We have been apprised about my condition, its natural course and possible complications. The need for regular follow-up and self-awareness of visual loss has been explained to us in a language that we can easily understand.

\section{Learning points}

- All patients of nephrotic syndrome (NS) presenting with visual complaints must be evaluated thoroughly.

- Retinal artery occlusion in a child with NS is mostly associated with a systemic hypercoagulable state. Urgent physician consultation is mandated to avoid multiorgan complications secondary to thromboembolism. respectively. Central retinal artery occlusion can cause profound visual impairment (and early presentation), whereas a branch retinal artery or smaller order retinal vascular occlusion can at times remain asymptomatic leading to late presentation. In such cases, indirect evidences like selective thinning of inner retinal layers or sclerosed arterioles can help in the diagnosis as in the present case. To the best of our knowledge, bilaterally symmetric branch retinal artery occlusion in a child with NS has never been reported in the literature (Medline search with key words 'branch retinal artery occlusion' and 'nephrotic syndrome'). Paediatricians should be aware of these sequalae. Any child with NS and visual complaints should be promptly referred to an ophthalmologist for a detailed evaluation. Patients diagnosed with fresh or old vascular occlusion should be kept under adequate prophylaxis and follow-up for preventing a similar thromboembolic event happening in the eye or any other organs in the body.

Twitter Utpal Bhusal @the_utpal

Contributors SKP and TRP: conception of the idea, manuscript preparation and critical review. UB and KGP: data acquisition and manuscript preparation.

Funding The authors have not declared a specific grant for this research from any funding agency in the public, commercial or not-for-profit sectors.

Competing interests None declared.

Patient consent for publication Parental/guardian consent obtained.

Provenance and peer review Not commissioned; externally peer reviewed.

\section{REFERENCES}

1 Kerlin BA, Haworth K, Smoyer WE. Venous thromboembolism in pediatric nephrotic syndrome. Pediatr Nephrol 2014;29:989-97.

2 Vivarelli M, Massella L, Ruggiero B, et al. Minimal change disease. Clin J Am Soc Nephrol 2017;12:332-45.

3 Kerlin BA, Ayoob R, Smoyer WE. Epidemiology and pathophysiology of nephrotic syndrome-associated thromboembolic disease. Clin J Am Soc Nephrol 2012;7:513-20.

4 Mahmoodi BK, ten Kate MK, Waanders F, et al. High absolute risks and predictors of venous and arterial thromboembolic events in patients with nephrotic syndrome: results from a large retrospective cohort study. Circulation 2008;117:224-30.

5 Gheissari A, Attarzadeh $\mathrm{H}$, Sharif $\mathrm{H}$, et al. Steroid dependent and independent ocular findings in Iranian children with nephrotic syndrome. Int J Prev Med 2011;2:264-8.

6 Sinha S, Rau ATK, Kumar RV, et al. Bilateral combined central retinal artery and vein occlusion in a 3-year-old child with nephrotic syndrome. Indian J Ophthalmol 2018;66:1498-501.

7 Dwivedi A, Lakhtakia S. Comment on: bilateral combined central retinal artery and vein occlusion in a 3-year-old child with nephrotic syndrome. Indian J Ophthalmol 2019;67:312-3.

8 Dwivedi A, Dwivedi D, Chalisgaonkar C, et al. Purtscher-like retinopathy: a rare ocular finding in nephrotic syndrome. Oman J Ophthalmol 2018;11:42-5.

Copyright 2020 BMJ Publishing Group. All rights reserved. For permission to reuse any of this content visit

https://www.bmj.com/company/products-services/rights-and-licensing/permissions/

BMJ Case Report Fellows may re-use this article for personal use and teaching without any further permission.

Become a Fellow of BMJ Case Reports today and you can:

- Submit as many cases as you like

- Enjoy fast sympathetic peer review and rapid publication of accepted articles

- Access all the published articles

Re-use any of the published material for personal use and teaching without further permission

Customer Service

If you have any further queries about your subscription, please contact our customer services team on +44 (0) 2071111105 or via email at support@bmj.com.

Visit casereports.bmj.com for more articles like this and to become a Fellow 